\title{
“FORMAÇÃO ECONÔMICA DO BRASIL" DE CELSO FURTADO EM TRÊS DIMENSÕES: HISTÓRIA, ECONOMIA E HORIZONTE DE EXPECTATIVA
}

Celso Furtado's “The Economic Growth of Brazil” in three dimensions: history, economy, and horizon of expectation

\author{
Fábio Pádua dos SANTOS \\ Departamento de Economia e Relações Internacionais \\ Universidade Federal de Santa Catarina \\ fpadua@gmail.com
}

\begin{abstract}
RESUMO
Objetivo: O presente artigo tem por objetivo oferecer aos leitores de Formação Econômica do Brasil um posfácio ao clássico de Celso Furtado de modo a enriquecer a primeira leitura e suscitar algumas provocações. Métodos: O texto combina análise de história das ideias e sociologia do conhecimento como métodos de análise. Resultados: Argumentase que Formação articula três problemáticas: da análise econômica do passado; da historicização das leis econômicas; e da teoria para a ação. Esta articulação resultou em contribuições originais em três domínios: no cam po da historiografia, a caracterização do subdesenvolvimento como um fenômeno particular da civilização industrial; nas ciências econômicas, a proposição de uma teoria do subdesenvolvimento; e, no domínio das interpretações do Brasil, o padrão de crescimento econômico excludente e a questão regional para a integração nacional. Conclusões: Por fim, conclui-se que Furtado pretendeu construir um conhecimento sobre a realidade brasileira que não se apresentasse como forma de dominação. PALAVRAS-CHAVE: Celso Furtado; Desenvolvimento Econômico; Brasil.
\end{abstract}

\begin{abstract}
Objective: This article aims to offer The Economic Growth of Brazil readers a postscript to Celso Furtado's classic in order to enrich their first reading and provoke some reflections. Methods: The text combines history of ideas and sociology of knowledge as methods of analysis. Results: It argues that The Economic Growth of Brazil brings together three subjectsmatters: the economic analysis of the past; the historicization of economic laws; and theory for action. This interposition resulted in original contributions in three domains: in the field of historiography, the characterization of underdevelopment as a particular phenomenon of industrial civilization; in the economic sciences, the proposition of a theory of underdevelopment; and, in the field of interpretations of Brazil, the pattern of excluding economic growth a nd the role of the regional development for national integration. Conclusions: Finally, it concludes that Furtado intended to build a knowledge about the Brazilian reality which did not present itself as a form of domination.
\end{abstract}

KEYWORDS: Celso Furtado; Economic Development; Brazil.

Classificação JEL: B31, B52, N01, 01.

Recebido em:28-10-2020. Aceito em: 26-11-2020. 


\section{INTRODUÇÃO}

Formação Econômica do Brasil (1959) de Celso Furtado é um livro cuja releitura sempre provoca o prazer da primeira descoberta. Escrito de maneira clara e direta, compõe um conjunto muito seleto e restrito de outros trabalhos que se propuseram a pensar em profundidade a construção da modernidade no Brasil. O ângulo privilegiado é o econômico. Nem por isso a obra perde de vista o político e o cultural. Neste livro, Furtado (2003 [1959], p. 7) procurou esboçar "o processo histórico de formação da economia brasileira" a partir de "uma perspectiva o mais possível ampla". Ele queria "captar as inter-relações e as cadeias de causalidade que constituem a urdidura dos processos econômicos." Para tanto, reconstruiu o passado para oferecer ao leitor uma explicação das raízes do subdesenvolvimen to brasileiro. Nesta reconstrução, apoiou -se em recursos analíticos como Ionga duração, comparação e descrição. Espírito criativo, na ausência de evidências, valeuse de hipóteses contrafactuais e deduções para preencher as lacunas do passado. Sobre o fluxo do acontecer humano aplicou análise econômica para elucidar os dilemas da formação do mercado interno nos diferentes momentos da história brasileira. Em seu acerto de contas com o passado, Furtado expôs as bases do modelo brasileiro de desenvolvimento ao mesmo tempo em que esboçou uma perspectiva analítica original, o enfoque histórico-estrutural.

O presente texto tem por objetivo oferecer aos leitores de Formação Econômica do Brasil um posfácio ao clássico de Celso Furtado. A intenção é tão-somente enriquecer a primeira leitura suscitando algumas provocações. Como se pretende argumentar, Formação articula três problemáticas: da análise econômica do passado; da historicização das leis econômicas; e da teoria para a ação. Esta articulação resultou em contribuições originais em três domínios: no campo da historiografia, a caracterização do subdesenvolvimento como um fenômeno particular da civilização industrial; nas ciências econômicas, a proposição de uma teoria do subdesenvolvimento; e, no domínio das interpretações do Brasil, o padrão de crescimento econômico excludente e a questão regional para a integração nacional.

Para explorar a riqueza deste clássico, apresen ta-se incialmente o contexto no qual Formação Econômica do Brasil foi escrito e publicado. Em seguida, expõe-se o conteúdo do livro. Na sequência, explora-se a recepção da obra por diferentes pensadores sociais no Brasil e no exterior. Por fim, apresenta-se seu legado e atualidade através de um balanço 
crítico à luz das ciências sociais historicamente fundamentadas.

\section{CONTEXTO: A CONFLUÊNCIA DE VÁRIOS RITMOS}

Formação Econômica do Brasil é um livro e uma história. É sobretudo um produ to e uma crítica da cultura moderna. Para aprender, no sentido de captar seu significado, tomase emprestado de Marshall Berman o conceito de modernidade, para quem:

existe um tipo de experiência vital, de si mesmo e dos outros, das possibilidades e perigos da vida - que é compartilhada por homens e mulheres em todo o mundo, hoje. Designarei esse conjunto de experiências como 'modernidade'. Ser moderno é encontrar-se em um ambiente que promete aventura, poder, alegria, crescimento, autotransformação das coisas em redor - mas ao mesmo tempo ameaça de destruir tudo o que temos, tudo o que sabemos, tudo o que somos. A experiência ambiental da modernidade anula todas as fronteiras geográficas e raciais, de classes e nacionalidade, de religião e ideologia: nesse sentido, pode-se dizer que a modernidade une a espécie humana. Porém, é uma unidade paradoxal, uma unidade de desunidade: ela nos despeja a todos num turbilhão de permanente desintegração e mudança, de luta e contradição, de ambiguidade e angústia (BERMAN, 2007 [1982], p. 24).

Como comentou Perry Anderson (1986, p. 3 et seq.), para Berman, modernidade significa a experiência histórica que articula o processo de modernização, que tem origem com a ascensão do mercado mundial, e as transformações da subjetividade humana a que os indivíduos estão sujeitos. Nesta seção, caracteriza-se Formação Econômica do Brasil como produto cultural da forma que essa tensão ganhou expressão no Brasil contemporâneo e na maneira que Celso Furtado a experienciou. Para captar sua essência e seu potencial crítico, o contexto que deu origem ao Formação foi decomposto em três ritmos que se articulam dialeticamente: o tempo da vida do autor, o tempo moderno e o tempo brasileiro.

\subsection{O tempo da vida ${ }^{1}$}

A formação intelectual e a experiencia de homem público de Celso Furtado (19202004) até a publicação da primeira edição de Formação Econômica do Brasil (1959) coincidem com o espaço de experiência que engloba o apagar das luzes da Era das Catástrofes (1914-1945) e a esperança com as promessas e feitos da modernidade

\footnotetext{
1 Para uma introdução à vida e obra de Furtado, ver Mallorquín (2014) ou ainda D'Aguiar (2019).
} 
reinauguradas pela Era de Ouro (1945-1973). Aos 20 anos de idade, Furtado ingressou na Faculdade de Direito na então Universidade do Brasil, onde teve contato em 1942 com a sociologia alemã - em especial Max Weber (1864-1920) -, mesmo ano em que leu Joseph Schumpeter (1883-1950) e Karl Mannheim (1893-1943), que formariam, mais adiante, sua visão acerca da natureza do capitalismo. No ano seguinte, em 1943, o jovem estudante de direito foi investido no cargo de assistente de organização e de técnico de administração no Departamento Administrativo do Serviço Público (DASP), dando in ício à sua carreira de homem público. Período de Guerra, em 1944 prestou serviço militar no Centro de Preparação de Oficiais da Reserva, sendo convocado para compor a Força Expedicionária Brasileira que desembarcou na Itália em 1945. Estar na Europa neste momento propiciou um ângulo privilegiado de reflexão que o permitiu comparar o esforço de reconstrução da Europa com o esforço modernizante do Brasil. Tomado por um otimismo transformador, escreveu o ensaio Trajetória da democracia na América, o qual foi agraciado em 1946 com o prêmio Franklin D. Roosevelt, do Instituto Brasil-Estados Unidos. Ao final da Segunda Grande Guerra, Furtado permanece na Europa para completar sua formação. Entre períodos de estudo na Sorbonne e na London School of Economics, em 1948, Furtado apresentou sua tese de doutoramento em economia pela Universidade de Paris, intitulada A economia colonial no Brasil nos séculos XVI e XVII. Iniciava-se a gestação de uma das mais importantes obras do pensamento social brasileiro. ${ }^{2}$

Após a apresentação da tese, Furtado retornou ao Brasil com rápida atuação na Fundação Getúlio Vargas, onde, no ano seguinte, em 1949, integrou o quadro técnico da Comissão Econômica para América Latina (CEPAL) em Santiago do Chile somando esforços junto a Raúl Prebisch (1901-1986) e outros profissionais na identificação dos problemas latino-americanos do desenvolvimento, e na apropriação crítica das teorias do desenvolvimento. Deste encontro resultaram a formulação original do enfoque históricoestrutural e a especificação do modelo centro-periferia para explicartanto o caráter desigual do desenvolvimento capitalista mundial quanto a condição de subdesenvolvimento da América Latina. $^{3} \mathrm{O}$ enfoque e o modelo marcaram definitivamente a perspectiva que Furtado empregaria anos depois para a elaboração de Formação.

Resultado destas primeiras reflexões, Furtado publica em 1950 seu primeiro ensaio de análise econômica na Revista Brasileira de Economia, da Fundação Getúlio Vargas:

\footnotetext{
2 Para situar a contribuição de Furtado em relação ao pensamento social brasileiro, ver Ricupero (2008).

3 Para um exame mais detalhado do enfoque histórico-estrutural e seus desdobramentos ver Sunkel e Paz (1970), Rodríguez (2009) e Santos (2011).
} 
Características gerais da economia brasileira. Em 1951 Furtado viajou aos Estados Unidos rumo a um in tercâmbio de experiências com as principais instituições de ensino e pesquisa dedicadas à temática do desenvolvimento. Nesta viagem teve a oportunidade de debater com autores renomados como Wassili Leontieff (1906-1999) e Walt Rostow (1916-2003). Fruto deste diálogo, em 1952 Furtado publicou o artigo que Ihe deu notoriedade internacional Formação de capital e desenvolvimento econômico, publicado na Revista Brasileira de Economia e traduzido no mesmo ano pela Internacional Economic Papers. Em 1953, ainda como economista da CEPAL, Furtado foi transferido para o Brasil para presidir o Grupo CEPAL-BNDE, cujo acordo de cooperação técnica visava elaborar um diagnóstico da econômica brasileira e propor um programa de desenvolvimento apoiado em técnicas de planejamento. O relatório técnico resultante, denominado Esboço de um programa de desenvolvimento, período de 1955-1962, tornou-se posteriormente a principal referência para a elaboração do Plano de Metas do Governo Juscelino Kubitschek.

Antes disso, em 1954, sob a efervescência das ideias cepalinas, das iniciativas de desenvolvimento, da ruptura abrupta do Governo Vargas e do debate sobre as reformas de base, Furtado publicou seu primeiro livro, A economia brasileira, outra peça importante que viria compor a última parte do livro Formação Econômica do Brasil. Com este livro, Fu rtado se projetara em definitivo no debate público nacional disputando o enfoque científico que a escola ortodoxa pretendia monopolizar desde a FGV. Para dar voz às perspectivas heterodoxas, Furtado criou no Rio de Janeiro o Clube de Economistas com o objetivo de publicar a Revista Econômica Brasileira e, através dela, difundir estudos de economia aplicada e estimular trabalhos interpretativos de cunho teórico. Em 1956, Furtado afastase do Brasil para cumprir novas obrigações junto à CEPAL na Cidade no México. Neste mesmo ano o autor publica outro livro, Uma economia dependente, formado por extratos do livro de 1954.

Entre a apresentação de sua tese de doutorado e sua experiência na CEPAL, foi se tornando cada vez mais claro para Furtado a importância da dinâmica econômica para a promoção do desenvolvimento. Isto o levou, em 1957, ao King's College da Universidade de Cambridge, Inglaterra, para se dedicar ao estudo da temática sob a supervisão de Nicholas Kaldor. Foi neste período, entre elaborações teóricas e acertos com o passado, que nascera Formação Econômica do Brasil, que seria publicado em janeiro de 1959. Neste sentido, a obra mais popular de Celso Furtado expressa não apenas seu amadurecimento intelectual, decorrente de sua prática, como também carrega e compõe o espírito do tempo da reconstrução da ordem mundial do pós-Guerra. 


\subsection{O tempo moderno}

Como se pode notar na descrição anterior, o tempo da vida de Furtado coincide como o tempo moderno sufocado pelas ruínas do mecanismo de equilíbrio de poder, do padrãoouro, da economia de mercado e do Estado liberal (cf. POLANYI, 2012). Furtado se formou como intelectual e teve o início de sua vida pública num contexto em que a sobrevivência da civilização ocidental do século XIX estava em xeque pela eclosão da Segunda Grande Guerra. Uma civilização, conforme descreve Hobsbawm,

[...] capitalista na economia; liberal na estrutura legal e constitucional; burguesa na imagem de sua classe hegemônica característica; exultante com o avanço da ciência, do conhecimento, da educação e também com o progresso material e moral; e profundamente convencida da centralidade da Europa (...); uma Europa cujas populações (...) haviam crescido até somar um terço da raça humana; e cujos maiores Estados constituíam o sistema da política mundial. (HOBSBAWM, 1995, p. 16)

As duas grandes guerras e o colapso econômico de 1929, minaram as condições para a expansão da democracia liberal como modo mundial e nacional de governos. $O$ desmoronamento da economia de mercado retirou as condições de consentimento e legitimidade da política liberal. Rompeu com isso o consenso mínimo requerido para a conciliação das tensões sociais por meio da democracia e chamou governos a dirigir em um arranjo in stitu cional no qual cabia ao Estado prover as regras básicas de convívio social, tornando-o obsoleto. Fez, portanto, da democracia um mecanismo de formalização de grupos irreconciliáveis (cf. HOBSBAWM, 1995, pp. 138-143).

Não obstante, as reações autoritárias à crise, que se apresentaram como alternativas históricas à civilização do século XIX nas primeiras décadas do século $X X$, não foram capazes de aniquilar os valores e as instituições liberais no Ocidente. Após a derrota das forças sociais fascistas e nazistas por uma aliança bastante incomum entre liberalismo e comunismo, o renascimento da democracia como forma de governo mundial do pós-guerra ampliou o horizonte de expectativa tanto nos países do centro da economia-mundo capitalista quanto nos países da periferia ocidental, que encontraram respaldo no princípio da autodeterminação nacional para a continuidade dos processos de construção nacional. ${ }^{4}$

\footnotetext{
${ }^{4}$ Para articular o tempo da vida de Furtado ao tempo moderno, toma-se emprestado de Reinhart Koselleck (2006, pp. 309-314) os conceitos de "espaço de experiência" e "horizonte de expectativa" para quem "a experiência é o passado atual, aquele no qual acontecimentos foram incorporados e podem ser lembrados. $\mathrm{Na}$ experiência se fundem tanto a elaboração racional quanto as formas inconscientes de comportamento, que que não estão mais, ou que não precisam mais estar presentes no conhecimento. Além disso, na
} 
Por meio de instituições supraestatais, como o Acordo de Bretton Woods, o Acordo Geral de Tarifas e Comércio e a Organização das Nações Unidas e de sua política externa orientada pela autodeterminação nacional, os Estados Unidos exerceram seu poder hegemônico mundial ao encorajar a adoção de sistemas democráticos de governo e a integração econômica do ocidente como forma de combate ao avanço do comunismo.

No Brasil, a criação da SUMOC (Superintendência da Moeda e do Crédito) em 1945 e a adesão ao padrão ouro-dólar foram os primeiros passos na integração à ordem hegemônica estadunidense. O apelo ideológico viria pela Doutrina Truman (1947), segundo a qual a estabilidade da ordem mundial só seria alcançada com a consolidação do sistema de livre iniciativa. Ao promover o Tratado Interamericano de Assistência Recíproca de 1947 (apoio econômico e financeiro), o "Programa Ponto 4" de 1949 (disseminação de conhecimento técnico) e a Lei de Assistência Econômica Estrangeira de 1950 (cooperação para produção de matérias-primas estratégicas), os EUA adensaram as relações econômicas de longo prazo com o Brasil, na medida em que espraiaram recursos financeiros e difundiram o conhecimento técnico necessário ao planejamento e à coordenação conjunta de atividades econômicas em nível mundial. No Brasil, talvez a expressão mais forte desse movimento tenha sido a formação da Comissão Mista BrasilEstados Unidos em 1951, o estabelecimento da CEPAL no Brasil e a criação do BNDE em 1952. Com efeito, estes são exemplos de como a hegemonia estadunidense pouco a pouco foi se articulando com o desenvolvimento "nacional" do país e indicam os mecanismos através dos quais foram construídas as condições necessárias à integração dos diversos "sistemas nacionais de produção", via Investimentos Estrangeiros Diretos (IEDs).

Dessa perspectiva, promover a diversificação da estrutura produtiva brasileira - por financiamento externo ou pelo ingresso de IEDs - significava fortalecer, simultaneamente, a economia e a hegemonia estadunidenses com base em um regime de acumulação

experiência de cada um, transmitida por gerações e instituições, sempre está contida e é conservada uma experiência alheia." "Algo semelhante se pode dizer da expectativa: também ela é ao mesmo tempo ligada à pessoa e ao interpessoal, também a expectativa se realiza no hoje, é futuro presente, voltado para o aindanão, para o não-experimentado, para o que apenas pode ser previsto. Esperança e medo, desejo e vont ade, a inquietude, mas também a análise racional, a visão receptiva ou a curiosidade fazem parte da expectativa e a constituem." "Horizonte quer dizer aquela linha por trás da qual se abre no futuro um novo espaço de experiência, mas um espaço que ainda não pode ser contemplado. A possibilidade de se descobrir o futuro, apesar de os prognósticos serem possíveis, se depara com um limite absoluto, pois ela não pode ser experimentada." Deste ponto de vista, pode-se assumir que Formação Econômica do Brasil de Celso Furtado representou um prognóstico daformação da sociedade brasileira na era das expectativas crescente, portanto, no interior do tempo moderno, na medida em que na sua crítica à construção do modernidade no Brasil viu na abertura das estruturas de poder e na orientação planejada do processo de industrialização a possibilidade de superação do subdesenvolvimento. 
autocentrado (cf. ARRIGHI, 1996). Do ponto de vista da demanda, os Estados Unidose a Europa dependiam das matérias-primas e produtos primários oriundos das áreas periféricas; ao passo que, do ponto de vista da oferta de manufaturados, a elevação do nível da renda dos países da periferia beneficiava setores da indústria e da agricultura estadunidenses, uma vez que os mercados nacionais em formação na periferia se convertiam em mercados externos e alargavam o escopo da acumulação capitalista. Portanto, na visão do Estado hegemônico, fortalecer as economias subdesenvolvidas significava, naquele contexto, reforçar o mercado mundial necessário à reconstrução da Eu ropa e, por consequência, à reordenação da economia-mundo capitalista sob hegemonia dos EUA. Daí a relevância do debate sobre o desenvolvimento travado pelo pensamento social brasileiro, que expressava o "espírito do tempo" no qual o processo de modernização ocupava lugar central.

A práxis de Furtado articulou seu tempo de vida ao tempo moderno ao atuar como agente da reconstrução da ordem mundial do pós-guerra. Não obstante, os espaços de experiência nos quais Furtado esteve inserido somado à sua atitude intelectual crítica nos anos anteriores à publicação de Formação Econômica do Brasil, desenvolveu nele a consciência da relação en tre progresso técnico e o desenvolvimento desigual da economia mundial. A tensão entre a visão de mundo republicana e a experiência da modernização permitiu Furtado forjar seu primeiro entendimento sobre o subdesenvolvimento que, orientado para análise econômica do passado, faria de Formação uma denúncia contra os mecanismos de dependência sobre os quais se erguia a hegemonia estadunidense.

\subsection{O tempo brasileiro}

Para contextualizarmos Furtado e seu livro Formação, resta ainda um ritmo intermediário: o tempo brasileiro. Este representa o tempo da construção nacional, ou na felizexpressão de Fernando Novais (2005, pp. 183-203), da passagem para o novo mundo. Imediatamente após a emancipação política em 1822, ante uma vida social organizada à margem da economia de mercado, o problema nacional, lembra Wanderley Guilherme dos Santos (2006, p. 14), "consistia na redução das tendências centrífugas, com aspirações autonomistas, e promover compulsoriamente a integração para obter, ao final, o indispensável precipitado da identidade nacional." Buscou -se construir a coesão social na época do império através de símbolos episódicos dramáticos, ficando para o século $\mathrm{XX}$ 
edificar os fundamentos institucionais da modernidade no Brasil. A Revolução de 1930 assumiu para si esta responsabilidade ao enfrentar a crise da integração nacional, a crise da participação política e a crise da redistribuição de riqueza. A singularidade foi querer enfrentar simultaneamente essas três crises, que marcam a entrada de uma sociedade no mundo moderno (SANTOS, 2006), no contexto da era das catástrofes (HOBSBAWM, 1995). Toda a agitação política e social que marcou o interlúdio democrático brasileiro (1945-1964) continha em si as primeiras reações aos mecanismos de regulação social institucionalizados pelo nacional-desenvolvimentismo varguista. No contexto das reformas de base estavam em disputa duas estratégias de desenvolvimento:

a escolha entre uma proposta de um capitalismo nacional voltado principalmente para as forças econômicas, sociais e políticas que constituem a sociedade nacional e um capitalismo que lança mão dessas bases, mas beneficia-se em ampla medida, do intercâmbio com as multinacionais e faz, em certa escala, um jogo com elas (IANNI, 2004, p. 108)

Novamente, o tempo da vida de Furtado se desenrola neste momento privilegiado de entrecruzamento do tempo brasileiro ao tempo moderno: uma sociedade não mais exclusivamente oligárquica, porém ainda indecisa sobre os caminhos da modernização. Deste ponto de vista, Formação Econômica do Brasil se inscreve no suspiro democrático entre a Era Vargas (1930-1945) e o Regime militar (1964-1985) e pode ser visto como um prognóstico a favor do capitalismo socialmente regulado em bases republicanas para a superação do impasse da formação nacional brasileira. Como bem observou Marcos Valente (2009, p. 96), a crítica de Furtado "às estruturas de poder no Brasil é uma crítica republicana, e sua teoria do subdesenvolvimento tem uma dimensão normativa que tem fundamento republicano." Para Valente, a teoria de Furtado:

... não resulta apenas na recomendação de uma maior intervenção do Estado e do planejamento. Requer muito mais que isso, uma complexa rearticulação estrutural do conjunto das instituições políticas, sociais, econômicas e culturais, e que tem como fundamento básico a ideia de liberdade. $\mathrm{E}$ a noção de liberdade que Furtado apresenta contém todos os elementos do conceito de liberdade como não-dominação formulado na teoria neo-republicana (VALENTE, 2009, p. 96).

Quando se articulamos três tempos - o tempo moderno, o tempo brasileiro e o tempo da vida de Furtado - destaca-se a singularidade que Formação condensa: um livro que buscava naquele contexto uma alternativa histórica ao Brasil contra os mecanismos de dependência da ordem mundial liderada pelos EUA e contra as estruturas regionais autoritárias do poder oligárquico favorável a um processo de modernização excludente. A construção nacional como luta contra as desigualdades e como construção da liberdade 
ensejavam a paixão de Furtado pelo Brasil.

Celso Furtado parecia ter clareza frente a dialética do tempo histórico. Em suas memórias lembra que seu intuito ao escrever Formação Econômica do Brasil era ordenar suas ideias de Brasil, em especial sobre o desenvolvimento capitalista e as origens da economia brasileira. Queria, para tanto, elaborar um modelo da economia brasileira que permitisse apreender a dinâmica da formação do mercado interno em perspectiva histórica. Daí seu método de “... aproximar a História (visão global) da análise econômica...", que mais tarde ficou conhecido como enfoque histórico-estrutural ou estruturalismo latinoamericano. Como lembra a autor, "inclinei-me a pintar um vasto afresco." Deste modo, "o livro seria uma coleção de hipóteses com demonstrações apenas iniciadas ou sugeridas." (FURTADO, 2014, n.p.)

Apresentar algumas dessas hipóteses será o objetivo da próxima seção.

\section{O LIVRO}

Formação econômica do Brasil está divido em cinco partes. Na primeira, "fundamentos econômicos da expansão territorial", Furtado faz um voo panorâmico sobre as origens da economia colonial no contexto da expansão do império português na América até a crise do sistema colonial. Discute as particularidades da exploração mercantil escravista e do monopólio comercial. Com isso, delimita o quadro dentro do qual ele investiga a natureza da dinâmica da economia colonial. Nas partes seguintes são exploradas as características de cada ciclo econômico. Na segunda parte, "economia escravista de agricultura tropical (séculos XVI e XVII), o autor discute a economia açucareira e a formação do complexo nordestino. Na terceira parte, "economia escravista mineira (século XVIII), Furtado trata do papel do ouro não só do ponto de vista da interiorização da colônia, mas, sobretudo, da integração econômica das regiões meridionais que tiveram lugar à época. Na quarta parte, "economia de transição para o trabalho assalariado (século XIX)," Furtado explora o complexo cafeeiro, destacando a centralidade do assalariamento para a formação do mercado interno. Por fim, na última parte, "economia de transição para um sistema industrial (século XX)", o autor localiza as origens da economia in dustrial no Brasil na crise da economia cafeeira, destacando as especificidades da industrialização na periferia do sistema capitalista mundial.

O fio condutor da explicação histórico-estrutural furtadiana em Formação Econômica 
do Brasil é a análise econômica do passado com base no exame do fluxo da renda nos diferentes ciclos econômicos (açúcar, ou ro, café e in dú stria) que marcaram a instituição de uma economia monetária da produção no interior do espaço jurídico-político que veio a se chamar Brasil. A preocupação central de Furtado era compreender as origens e as especificidades da industrialização no Brasil e explicar suas consequências para a formação do mercado interno e de seu papel no processo de construção nacional.

Para tanto, Furtado explorou para cada ciclo econômico a relação entre excedente econômico (processo de formação da renda e de acumulação de capital) e sistemas de dominação, levando em consideração: o regime de trabalho dominante; a posição da atividade econômica principal na divisão internacional do trabalho; os mecanismos de intercambio desigual vigentes em cada período; o potencial de diferenciação da estrutura produ tiva de cada atividade econômica articulada ao comércio internacional; a capacidade dos poderes locais de se apropriar de parcela do excedente gerado; e a disposição dos mesmos para efetivar o emprego produ tivo deste excedente de modo a aprofundara divisão regional do trabalho e sustentar uma crescente taxa de acumulação de capital.

Desta perspectiva, a especificidade da economia colonial, seja a economia açucareira, seja a economia mineira, é a escravidão e a externalidade da acumulação, isto é, o circuito da acumulação se encerrava foram do Brasil, drenando parcela considerável do excedente. Apesar de o açú care o ou ro impulsionarem processos de integração regional por meio de atividades econômicas complementares através da divisão do trabalho (complexo nordestino, no caso do açúcar, e o complexo meridional, no caso do ouro), a capacidade de crescimento da renda média no longo prazo estava sujeita à dinâmica da economia europeia. Na visão de Furtado, o caráter extrovertido e escravista da exploração colonial não requeria o alargamento da economia monetária da produção colonial, concentrando quase que exclusivamente nas elites locais a pequena parcela da renda mundial gerada pelo comércio dos gêneros coloniais. Sem transbordar "para dentro", a renda (que poderia ser redistribuída aos produtores diretos ou ser convertida em desenvolvimento tecnológico autóctone, base para ganhos de produtividade) era despendida no circuito de consumo de luxo. Para Furtado, a escravidão promovia a separação entre o sistema de produção colonial, orientado para a necessidades da economia europeia em expansão, e o consumo colonial, baseado na subsistência. Isto mitigava as vantagens do crescimento demográfico sobre o nível da renda de modo desfavorável a acumulação de capital sustentada no próprio mercado regional. (cf. FURTADO, 2003 [1959], p. 58) Este padrão de crescimento econômico, que caracteriza o 
período colonial, Furtado denominou de modelo primário-exportador.

No séculoXIX, este modelo teve seus limites expostos. A consolidação da civilização industrial na Europa redefiniu não só as condições de integração dos espaços periféricos na divisão internacional do trabalho (novos níveis de produtividade e escala) e no sistema interestatal (desintegração do sistema colonial americano e formação dos Estados nacionais), como também, mitigou as fontes de renovação da mão-de-obra escrava africana sobre a qual a economia colonial se apoiava. Isto fez da economia cafeeira um ponto de inflexão do ponto de vista da formação do mercado interno brasileiro. Para Furtado, na base desta inflexão estava a transformação do regime de trabalho. A partir da segunda metade do século XIX, a substituição do escravismo pelo assalariamento (através das migrações europeias) permitiu gradativamente a redistribuição de parcela da renda em favor da mão de obra. Com isso, parte da produção material da vida deixou de ser suprida em bases exclusivamente de subsistência e passou a ser mediada por mecanismos monetários, ou seja, integrou parcela do consumo ao sistema de produção. Apesar da atividade cafeeira reproduzir o padrão colonial monocultorvoltado para o comércio internacional, a introdução do assalariamento imprimiu nova dinâmica ao fluxo da renda distinta das economias açucareira e mineira. "A massa de salários pagos no setor exportador vem a ser, por conseguinte, o núcleo de uma economia de mercado interno", observou Furtado (2003 [1959], p. 158). Nesta etapa, o crescimento da economia brasileira passou a se dar com base em dois mecanismos: pelo crescimento das exportações e pelo multiplicador interno, este último derivado da massa de salários pagos no setor exportador.

A indústria no Brasil e as especificidades do sistema industrial brasileiro tiveram origem, para Furtado, na especificidade dinâmica da crise da dependente economia cafeeira. Segundo o autor, a combinação de uma economia primário-exportadora assalariada, sujeita aos mecanismos do padrão-ouro, e de uma larga faixa de economia de subsistência, imprimiu uma dinâmica específica de propagação da crise que condenava a economia de mercado interno ao crescente desequilíbrio no balanço de pagamentos e à inflação monetária. Na raiz desses fenômenos estava a ausência de estímulos à ganhos de produtividade baseados em progresso tecnológico e o restrito grau de monetização da economia de mercado interna que, na fase de prosperidade (de al ta do preço) concentrava a renda nos produtores e, na fase de contração (de queda do preço do café), socializava as perdas do balanço de pagamentos através de políticas de preservação da renda do setor exportador, ora via correção da taxa de câmbio ora via expansão do crédito. Para Furtado, apesar da não eliminação dos déficits do balanço de pagamento e da inflação, a política de 
manutenção da renda monetária do setor exportador na década de 1930 permitiu a manutenção da demanda efetiva e do nível de emprego da incipiente economia nacional que, frente ao cataclisma mundial (das duas grandes guerras e da crise de 1929), teve sua estrutura de preços relativos alterada, deslocando o centro dinâmico da acumulação de capital das exportações para o investimento substitutivo de importações.

Com isso, teve in ício ou tro ciclo econômico, o da in dustrialização por substituição de importações. Nos anos próximos à publicação de Formação, Furtado estava preocupado com o surgimento de desigualdades socioespaciais decorrentes da industrialização dependente. Em sua interpretação, além da tendência ao desequilíbrio externo e à inflação estrutural, fenômenos aos quais a economia brasileira estava sujeita, a tendência à concentração regional da renda, que pressionava a migração de contingentes populacionais das regiões mais pobres (nordeste) para as mais ricas (sul), colocava em xeque o processo construção nacional. "Essa disparidade de níveis de vida, que se acentua atualmente entre os principais grupos da população do país, poderá dar origem a sérias tensões regionais", observou Furtado (2003 [1959], p. 248).

Naquele contexto, o governo não dispunha de mecanismos cambiais e tarifários para corrigir disparidades nos marcos do mercado interno. Do ponto de vista da política econômica, Furtado compreendia que a preocupação central do governo deveria ser a promoção de uma nova forma de integração da economia nacional que aproveitasse os recursos e fatores de maneira mais racional. Isto exigiria tanto a ruptura de formas arcaicas de exploração econômica e de dominação ${ }^{5}$ quanto uma visão de conjunto capaz de mobilizar recursos e fatores em escala nacional. (cf. FURTADO, 2003 [1959], p. 251)

"Numa economia da livre empresa essa coordenação se faz um pouco ao acaso, e a probabilidade que tem cada um de fruir o máximo de vantagens indiretas é tanto maior quanto maior é o número de indivíduos que estão atuando simultaneamente" (FURTADO,

\footnotetext{
${ }^{5} \mathrm{Na}$ raiz dessa superação estava a relação social historicamente construída ao longo dos ciclos econômicos anteriores e que resultou da peculiar interação entre a monocultura voltada para exportação, a abundância de terras e a larga faixa de economia de sub sistência. Como bem observou Furtado (2003 [1959], p. 127), "se bem que a unidade econômica mais importante da economia de subsistência fosse realmente a roça, do ponto de vista social a unidade mais significativa era a que tinha como chefe o proprietário de terras. A este interessava basicamente que o maior número de pessoas vivesse em suas terras, cabendo a cada um tratar de sua própria subsistência. Dessa forma o senhor de terras, no momento oportuno, poderia dispor de mão de-obra de que necessitasse. Demais, dadas as condições de que prevaleciam nessas regiões, o prestígio de cada um dependia da quantidade de homens que pudesse utilizar a qualquer momento e para qualquer fim. Em consequência, o roceiro da economia de subsistência, sem bem não estivesse ligado pela propriedade da terra, estava atado por vínculos sociais a um grupo, dentro do qual se cultivava a mística de fidelidade ao chefe como técnica de preservação do grupo social." Este tema foi posteriormente retomado por Furtado em "A estrutura agrária no subdesenvolvimento brasileiro", segunda parte de Análise do "modelo brasileiro.
} 
2003 [1959], p. 247). Não obstante, a análise de Furtado foi para demonstrar que não era este o caso da economia brasileira. Apesar do deslocamento do centro dinâmico, a pequenez da infraestru tu ra econômica em relação ao tamanho da populaçãoe ao território, e as limitações de seu sistema monetário, a economia de mercado interna não se encontrava apta para realizar o papel de coordenação das livres iniciativas. É neste sentido que, para Furtado, a visão de conjunto deveria ser organizada pelo Estado através das técnicas de planejamento. Tratava-se de planejar a liberdade e a igualdade. Levar adiante a industrialização significava avançar na escala da técnica e, com ela, abrir a possibilidade de liberar o "caboclo" da economia de subsistência a que se encontrava preso, convertendo-o em indivíduo sujeito a experenciar a modernidade.

A força do argumento de Formação provocou e ainda provoca distintas reações. $\mathrm{Na}$ próxima seção é apresentada a recepção da obra por diferentes pensadores sociais no Brasil e no exterior.

\section{RECEPÇÃO}

Não há dúvidas que Formação Econômica do Brasil é um clássico do pensamento social brasileiro com projeção internacional. Mesmo economistas de diferentes matizes teórico-ideológicas como Roberto Campos, Delfim Neto, Maria da Conceição Tavares, Mário Henrique Simonsen, Afonso Celso Pastore, Edmar Bacha, Luiz Gonzaga de Mello Belluzzo e André Lara Resende não discordariam dessa afirmação (cf. BIDERMAN; COZAC; REGO, 1996). Pode-se acrescentar à lista outros nomes relevantes como Paul Singer, José Serra, Antonio Barros de Castro, João Manuel Cardoso de Mello, João Sayad, Yoshiaki Nakano, José Alexandre Scheinkman, Fernando de Holanda Barbosa e Aloísio Mercadante (cf. MANTEGA; REGO, 1999). Nãoobstante, como lembra Ítalo Calvino (2007), "um clássico é uma obra que provoca incessantemente uma nuvem de discursos críticos sobre si, mas continuamente a repele para longe." A presente seção esforça-se para apontar algumas das principais críticas ao Formação nas últimas seis décadas.

Para tentar sistematizá-las, as críticas foram divididas em dois grupos, muito embora frequentemente interconectados: um de caráter teórico-metodológico e outro de caráter histórico-interpretativo. Dentre as críticas metodológicas, acusou-se de faltar à análise de Furtado uma teoria global que fosse capaz não apenas de articular elementos da infraestrutura e da superestrutura, mas de incluir fatores subjetivos/espirituais dos atores 
sociais (cf. ARENA, 2009 [1959]; SÁ, 2009 [1959]). Consequentemente, sugeriu-se que a explicação histórico-estrutural de Furtado incorre em "animismos" (cf. ARENA, 2009 [1959]), bem como em certo economicismo (cf. ARENA, 2009 [1959]; SÁ, 2009 [1959]; SZMRECSÁNYI, 2009 [1999]). Renato Arena (2009 [1959]), apontou ainda outra incoerência teórica de Furtado ao sugerir que este propôs implicitamente uma integração entre categorias marxistas e keynesianas sem explicação prévia das possibilidades de articulação de paradigmas tão distintos. Paul Singer (2009 [1959]), por outro lado, se absteve de críticas externas. Ao reconhecero esforço de Furtado para historicizaras teorias econômicas, bem como para reconstruir o passado nacional, Singer identificou uma incoerência interna ao pontar a dificuldade do autor em se libertar das próprias teorias que se propôs criticar. Outra linha de crítica se direcionava a precariedade da base de dados utilizada por Furtado. Alien H. Lester (2009 [1960]), por exemplo, questionou as estimativas de fluxo da renda, ao passo que Hans G. Muller (2009 [1963]) fez objeções aos cálculos do multiplicador. Por fim, a própria objetividade de Formação foi questionada quando se acusou Furtado de possuir viés industrialista (cf. SÁ, 2009 [1959]) bem como de defender a promoção de um capitalismo autônomo (cf. WÖHLCKE, 2009 [1975]).

No que diz respeito ao caráter histórico-interpretativo de Formação, as críticas se relacionaram às inconsistências interpretativas ora de fatos históricos, ora do papel das instituições e ora de processos sociais mais gerais. Por exemplo, Nelson Werneck Sodré (2009 [1959]) acusou Furtado de desconhecer a história. Renato Arena (2009 [1959]), por sua vez, apontou que este desconhecimento se manifestou nas interpretações concernentes ao Tratado de Methüen e ao episódio da Proclamação da República. Com relação à escravidão, Fragoso e Florentino (2001) alegam que Furtado não só reduziu a África a um simples viveiro de mão de obra como também excluiu da formação colonial a reprodução física dos escravos. Já do ponto de vista do caráter da política econômico, Carlos Peláez (1972) não concorda com Furtado com relação ao caráter keynesiano dos mecanismos de defesa do café. No que tange ao processo de industrialização no Brasil, Hans G. Muller (2009 [1963]) destacou o silêncio de Furtado em relação ao papel do capital estrangeiro na formação do capital industrial no Brasil, e Ignacy Sachs (2009 [1967]) discordou de Furtado ao não considerar a inflação como alternativa única de financiamento da indústria.

Posto desse modo, percebe-se que, apesar de pertinentes, as críticas direcionados ao Formação não afetam o núcleo de sua argumentação: a análise do fluxo da renda e sua relação com a ascensão de uma economia capitalista no Brasil, conforme apresentado na 
seção anterior. Mais cruciais foram as lacunas deixadas por Celso Furtado para pensar a transição ao Brasil contemporâneo e caráter desigual da modernização da periferia do sistema mundial capitalista. Por este caminho, Fernando Novais (2009 [1961]) fez duas observações pertinentes.

Em primeiro lugar,

Afigura-se insuficiente a simples vinculação do fenômeno [as diferentes formas de fluxo de renda] ao aparecimento do trabalho assalariado; este processo, na realidade, resulta, por sua vez, de uma convergência de fatores, que serão, posteriormente, ativados pelo próprio trabalho livre em expansão. De fato, pressupondo um certo grau de divisão do trabalho, a instauração do trabalho assalariado aciona o processo de mercantilização da produção e integração do sistema de trocas; em outras palavras, a mercantilização da força de trabalho, fruto da produção mercantil, é condição para sua expansão e penetração em todo o organismo social. Ao mesmo tempo, o trabalho livre pressupõe o trabalhador desprovido de meios de produção abrindo caminho para a constituição da produção capitalista fundamento da nova forma de repartição e multiplicação da renda analisada no texto. Nesta perspectiva, a investigação, para aprofundar a análise até as determinações mais internas do processo histórico, deveria esboçar as etapas de instauração das condições capitalistas de produção no Brasil (NOVAIS, 2009 [1961], p. 382).

Este foi o caminho tomado João Manuel Cardoso de Mello (1984 [1975]) ao discutir o conceito de economia colonial e revisitar as raízes do capitalismo retardatário a partir da identificação de distintos padrões de acumulação nas diferentes etapas de constituição do modo especificamente capitalista de produção no Brasil (cf. TAVARES, 1998 [1974]) e noutros países (cf. OLIVEIRA, 2003 [1985]).

A segunda observação de Novais é igualmente pertinente:

[...] é impossível desvendar esse processo de constituição de uma economia capitalista no Brasil sem integrá-lo com um elemento do processo mais geral de formação e desenvolvimento do capitalismo moderno. Não resta dúvida de que este livro traz uma notável contribuição no sentido de explicar as relações da economia brasileira com o mercado mundial nas várias fases de sua história, mas as vinculações sistemáticas se inserem num outro nível. Assim, seria preciso analisar a posição das economias escravistas coloniais, e a do Brasil entre elas, geradas dentro do sistema capitalista numa fase de sua formação (a própria explicação da escravidão colonial somente nesta perspectiva adquire sentido), e o modo pelo qual, numa etapa superior de desenvolvimento, o capitalismo industrial promoverá a superação dessas estruturas outrora necessária e já agora obsoletas (NOVAIS, 2009 [1961], p. 382).

Deste ponto de vista, iluminam-se as contribuições como, por exemplo, a do próprio Fernando Novais (1995 [1979]) que, ao definir a categoria Antigo Sistema Colonial, integrou a contribuição de Furtado à de Caio Prado Jr. (2008 [1942]), articulando a colonização à transição do capitalismo comercial ao capitalismo moderno. Luis Felipe de Alencastro 
(2000) também en riqueceu esta paisagem a partir da perspectiva do mercado atlântico sul, explorando o caráter extrovertido da gestação do Brasil, em especial, da constituição de seu mercado de trabalho, primeiro com o tráfico de escravos, depois com o trato de migrantes. No esforço de inserir o Brasil no sistema-mundo moderno, destacam-se ainda os trabalhos de Pedro A. Vieira (2012, 2014) e Rosangela L. Vieira (2012) que procuraram articular, a partir do conceito de cadeia mercantil, os ciclos econômicos do açúcar e do café à ascensão e desenvolvimento da economia-mundo capitalista. Neste nível de análise, Eduardo Mariutti (2009) investigou a relação entre o colonialismo e o imperialismo, e o surgimento de uma semiperiferia. Já, do ponto de vista das bases da formação territorial do Brasil e suas configurações regionais nos quadros dos sistema-mundo moderno, Antonio Carlos Robert Moraes (2000) e Bertha K. Becker e Claudio A. G. Egler (2003) também deram boas contribuições.

Entre erros e acertos, Formação Econômica do Brasil continua sendo um livro atual porque convida seus leitores a pensar o Brasil de maneira não convencional. Por isso é uma referência obrigatória para a compreensão do debate sobre a formação do Brasil contemporâneo na história do capitalismo ocidental. Após sessenta anos de sua primeira edição: que herança este clássico deixa às futuras gerações?

\section{LEGADO E ATUALIDADE}

No campo da história do pensamento econômico brasileiro, Guido Mantega (1989, p. 29) assinalou que Formação Econômica do Brasil demarca, em conjunto com Desenvolvimento e Subdesenvolvimento, "a passagem do pensamento econômico brasileiro da pré-história para a história," lançando as bases para o modelo de substituição de importações (cf. MANTEGA, 1984, p. 78 et seq.). Ricardo Bielschowsky (2000 [1989], p. 162) argumentou que o clássico de Furtado "correspondeu a um trabalho de consolidação da consciência desenvolvimentista brasileira, que ele fundamentou com uma bem constituída argumentação histórica", ou, como resumiu posteriormente, uma "obra-prima do estruturalismo cepalino" (cf. BIELSCHOWSKY, 2009). Luis Carlos Bresser Pereira (1997) afirmou que Formação elevou Furtado ao status de intérprete do Brasil pela importância decisiva que cumpriu para a interpretação nacional burguesa ao propor a superação do subdesenvolvimento por meio da industrialização planejada. 
Embora haja um esforço de conversão de Celso Furtado em marco do cânon ${ }^{6}$ desenvolvimentista no debate econômico brasileiro, o presente texto buscou avaliar a contribuição de Formação Econômica do Brasil para a construção de uma ciência social historicamente fundamentada, avaliando sua herança e atualidade para o pensamento crítico do século XXI. Para tanto, é preciso aprofundar e expandir a observação que, a este respeito, fez João Manuel Cardoso de Mello:

A obra de Celso Furtado, para mim, é a única dentre a dos economistas brasileiros que tem um significado claramente universal. (...) Ferramentas básicas da análise econômica - a idéia de excedente econômico da Economia Política Clássica e a macrodinâmica keynesiana - são utilizadas para pensar articuladamente a história do capitalismo e a história econômica do Brasil. Como resultado surgem, de um lado, uma teoria do subdesenvolvimento e, de outro, uma interpretação do desenvolvimento do capitalismo brasileiro (MELLO, 1999, pp. 191-192)

Neste caso, para destacar a potência universal de Formação é preciso antes cruzar as linhas divisórias das disciplinas e estabelecer o diálogo entre a economia e as demais ciên cias sociais, bem como entre as ciências sociais e a história, um debate contemporâneo ao período de gestação do livro.

Karl Polanyi (2012 [1944]) assinalou que todos os ramos das ciências sociais, estabelecidas no século XIX, foram edificados sobre a hipótese de Adam Smith da propensão natural humana à troca, o que resultou na mentalidade de mercado que deu origem à falácia economicista. Tal falácia consistiria no erro lógico no qual a economia humana é equiparada a forma específica do mercado formador de preço. Polanyi argumentava que o conceito formal de economia desvincula a produção material da vida dos costumes e tradições, induzindo historiadores econômicos a transpor sem questionamento a dinâmica da moderna economia de mercado para ou tras sociedades em diferentes tempos históricos. Polanyi não colocou em dúvida a análise econômica. Seu objetivo foi estabelecer os limites históricos e institucionais do mercado formador de preço como mecanismo de regulação social. Com isso, ele pretendia transcender as limitações inerentes à análise econômica, contribuindo para uma teoria geral da organização econômica.

Nesse empreendimento, as reflexões de Fernand Braudel (1992 [1959], p. 43) somam esforços à crítica de Polanyi a partir da teoria dos tempos históricos segundoa qual a longa duração seria "indispensável a uma metodologia comum das ciências do homem." Para o historiador francês, a longa duração, aliadas às flutuações econômicas, políticas e

\footnotetext{
${ }^{6}$ Cf. Nunes e Bianchi (1999)
} 
culturais, permite comparar eventos aparentemente estranhos entre si e, deste modo, acessar as estruturas sociais e a dinâmica da mudança social de longo prazo.

Sob os ângulos da falácia economicista e da longa duração, o livro Formação Econômica do Brasil apresenta tensões internas que remetem aos êxitos e dificuldades de construção de uma ciência social historicamente fundamentada. A análise do processo de formação da renda e da acumulação de capital nos diferentes ciclos econômicos, permitiu a Furtado reconstruir, por meio de comparações através do tempo e do espaço, a formação do mercado interno, destacando as semelhanças e diferenças entre os ciclos do ponto de vista do potencial de diferenciação da divisão do trabalho, de sua capacidade de integração regional e do crescimento da renda média no longo prazo. ${ }^{7}$ Isto permitiu Furtado explicitar as diferenças de dinâmica econômica entre economias desenvolvidas e subdesenvolvidas (por exemplo, quando con trapõe EUA e Brasil), destacando o fenômeno da dependência e sua centralidade para a compreensão da economia brasileira. Portanto, em sua análise econômica do passado, 8 Furtado reconstruiu o passado brasileiro para explicar as diferenças entre os modelos de desenvolvimento primário-exportador e de in dustrialização por substituição de importações a partir das possibilidades da construção nacional apoiada no mercado interno no contexto da expansão da civilização industrial.

Além disso, Furtado, ao examinar os meandros da modernização capitalista na periferia do sistema mundial, constatou, diferentemente da teoria da modernização e de grande parte da economia do subdesenvolvimento, ${ }^{9}$ a existência de princípios de variação do processo de modernização, apontando as necessidades de elaboração teórica compatíveis com realidades singulares. ${ }^{10}$ Daí seu esforço em Formação para caracterizar - Brasil na sua diversidade regional como realidade histórico-particular ilustrativa do subdesenvolvimento e da dependência. Daí seu ensejo de buscar elaborar uma teoria do subdesenvolvimento como historização das leis econômicas, delimitando contextos históricos dentro dos quais o saber econômico produzido pelo centro assumiria algum poder explicativo e normativo. Daí suas críticas a finalidade legada ao Estado que, ao invés de fomentar as bases materiais para o exercício da cidadania no marco de uma sociedade liberal, reafirmava os mecanismos de inserção nacional subordinada às custas da crescente

\footnotetext{
7 Para um exame da teoria econômica subjacente ao Formação Econômica do Brasil, ver Coutinho (2008).

8 Para uma discussão mais detalhada da concepção de história em Furtado, ver Paula (2015) e Boianovsky (2015).

9 Para uma visão ampla do debate à época sobre o desenvolvimento, ver Agarwala e Sing ([1958] 2010).

10 Para um exame das estratégias de comparação de grandes estruturas e largos processos para contornar os postulados perniciosos das ciências sociais, ver Charles Tilly (1984).
} 
concentração da renda e do aprofundamento das desigualdades socioespaciais. Para Furtado, a política econômica deveria estar subordinada à realização de uma sociedade nacional livre e igualitária. Neste sentido, o planejamento estatal assumiria papel central para a construção da liberdade.

Portanto, a interposição de problemáticas que o livro Formação Econômica do Brasil articula resultou em contribuições originais em três domínios distintos: no campo da historiografia, a caracterização do subdesenvolvimento como um fenômeno particular da civilização industrial; nas ciências econômicas, a proposição de uma teoria do subdesenvolvimento; e, no domínio da interpretação do Brasil, o padrão de crescimento econômico excludente e a questão regional para a integração nacional.

Visto deste ângulo, Formação não encerra a obra de Celso Furtado, ao contrário, constituiu-se na base a partir da qual o autor apoiou sua busca por uma visão global em conflito com o eurocentrismo dominante. Como observou Furtado (2003 [1959], p. 166), “ali onde a realidade se distanciava do mundo ideal da doutrina [econômica] supunha-se que tinha início a patologia social." Furtado pretendeu construir um conhecimento sobre a realidade brasileira que não se apresentasse como forma de dominação. Este princípionão deve jamais ser esquecido. Ainda que a "era" do desenvolvimento nacional como objetivo plausível possa ter chegado ao fim, Formação Econômica do Brasil lega às novas gerações uma atitude e um método comprometidos com a emancipação humana, base para a construção de um novo tempo do mundo estruturalmente igualitário.

\section{REFERÊNCIAS}

AGARWALA, A. N.; SINGH, S. P. (Org.). A economia do subdesenvolvimento. 2. ed. Rio de Janeiro: Contraponto, 2010.

ALENCASTRO, L. F. de. O trato dos viventes: formação do Brasil no Atlântico Sul. São Paulo: Companhia das Letras, 2000.

ANDERSON, P. Modernidade e revolução. Novos estudos CEBRAP, v. 14, p. 2-15, 1986.

ARENA, R. Resenha. In: FURTADO, C.; FURTADO, R. F. d'Aguiar(Org.). Formação Econômica do Brasil: edição comemorativa: 50 anos. São Paulo: Companhia das Letras, 2009. p. 350-360.

ARRIGHI, G. O longo século XX. Rio de Janeiro, RJ: Contraponto, 1996. 
BECKER, B. K.; EGLER, C. A. G. Brasil: uma potência regional na economia-mundo. $4^{\mathrm{a}}$ ed. Rio de Janeiro, RJ: Bertrand Brasil, 2003.

BERMAN, M. Tudo que é sólido desmancha no ar: a aventura da modernidade. São Paulo: Companhia das Letras, 2007.

BIDERMAN, C.; COZAC, L. F. L.; REGO, J. M. (Org.). Conversas com economistas brasileiros. São Paulo: Editora 34, 1996.

BIELSCHOWSKY, R. Formação Econômica do Brasil: uma obra prima do estruturalismo cepalino. In: ARAÚJO, T. P.; VIANNA, S. T. W.; MACAMBIRA, J. (Org.). 50 anos de Formação Econômica do Brasil: ensaios sobre a obra clássica de Celso Furtado. Rio de Janeiro: IPEA, 2009. p. 49-67.

BIELSCHOWSKY, R. Pensamento econômico brasileiro: o ciclo ideológico do desenvolvimentismo. 5. ed. Rio de Janeiro, RJ: Contraponto, 2000.

BOIANOVSKY, M. Between Lévi-Strauss and Braudel: Furtado and the historicalstructural method in Latin American political economy. Journal of Economic Methodology, v. 22, n. 4, p. 413-438, 2015.

BRAUDEL, F. Escritos sobre a história. São Paulo, SP: Perspectiva, 1992.

BRESSER-PEREIRA, L. C. Interpretações sobre o Brasil. In: LOUREIRO, M. R. (Org.). 50 anos de Ciência Econômica no Brasil. Rio de Janeiro: Editora Vozes, 1997. p. 17-69.

CALVINO, I. Por que ler os clássicos. São Paulo: Companhia das Letras, 2007.

COUTINHO, M. C. A teoria econômica de Celso Furtado: Formação Econômica do Brasil. In: LIMA, M. C.; DAVID, M. D. (Org.). A atualidade do pensamento de Celso Furtado. São Paulo: Francis, 2008. p. 139-159.

D'AGUIAR, R. F. (Org.). Celso Furtado: diários intermitentes, 1937-2002. São Paulo: Companhia das Letras, 2019.

FLORENTINO, M.; FRAGOSO, J. O arcaísmo como projeto: mercado atlântico, sociedade agrária e elite mercantil em uma economia colonial tardia: Rio de Janeiro, c. 1790-c. 1840. Rio de Janeiro, RJ: Civilização Brasileira, 2001.

FURTADO, C. Formação Econômica do Brasil. 32. ed. São Paulo, SP: Companhia Editora Nacional, 2003.

FURTADO, C. Obra autobiográfica. Edição Definitiva ed. São Paulo: Companhia das Letras, 2014.

HOBSBAWM, E. J. Era dos extremos: o breve século XX: 1914-1991. São Paulo, SP: Companhia das Letras, 1995.

IANNI, O. A "redemocratização" de 1946 e as tentativas de reorientação da política econômica. In: SZMRECSÁNYI, T.; GRANZIERA, R. G. (Org.). Getúlio Vargas \& a 
economia contemporânea. $2^{a}$ ed. São Paulo: Hucitec, 2004. p. 97-111.

KOSELLECK, R. Futuro passado: contribuição à semântica dos tempos históricos . Rio de Janeiro: Contraponto, 2006.

LESTER, A. H. Resenha. In: FURTADO, C.; FURTADO, R. F. d'Aguiar (Org.). Formação Econômica do Brasil: edição comemorativa: 50 anos. São Paulo: Companhia das Letras, 2009. p. 375-378.

MALLORQUÍN, C. Celso Furtado. In: PERICÁS, L. B.; SECCO, L. F. (Org.). Intérpretes do Brasil: clássicos, rebeldes e renegados. São Paulo: Boitempo, 2014. p. 287-304.

MANTEGA, G. A economia política brasileira. Petrópolis, RJ: Editora Vozes, 1984.

MANTEGA, G. Celso Furtado e o pensamento econômico brasileiro. Revista de Economia Política, v. 9, n. 4, p. 29-37, 1989.

MANTEGA, G.; REGO, J. M. (Org.). Conversas com economistas brasileiros II. São Paulo: Editora 34, 1999.

MARIUTTI, E. B. Colonialismo, imperialismo e desenvolvimento econômico europeu. São Paulo: Aderaldo \& Rothschild, 2009.

MELLO, J. M. C. de. Entrevista. In: MANTEGA, G.; RÊGO, J. M. (Org.). Conversas com economistas brasileiros II. São Paulo: Editora 34, 1999.

MELLO, J. M. C. de. O Capitalismo Tardio: contribuição à revisão crítica da formação e do desenvolvimento da economia brasileira. São Paulo, SP: Brasiliense, 1984.

MORAES, A. C. R. Bases da Formação Territorial do Brasil: o território colonial brasileiro no “longo século” XVI. São Paulo, SP: Hucitec, 2000.

MUELLER, H. G. Resenha. In: FURTADO, C.; FURTADO, R. F. d'Aguiar (Org.).

Formação Econômica do Brasil: edição comemorativa: 50 anos. São Paulo:

Companhia das Letras, 2009. p. 389-392.

NOVAIS, F. A. Aproximações: estudos de história e historiografia. São Paulo, SP: Editora Cosac Naify, 2005.

NOVAIS, F. A. Portugal e Brasil na crise do antigo sistema colonial (1777-1808). 6a. ed. São Paulo, SP: Editora Hucitec, 1995.

NOVAIS, F. A. Resenha. Formação Econômica do Brasil: edição comemorativa: 50 anos. São Paulo: Companhia das Letras, 2009. p. 379-383.

NUNES, R.; BIANCHI, A. M. Duas maneiras de contar a história do pensamento econômico. Revista de economia contemporânea, v. 3, n. 1, 1999.

OLIVEIRA, C. A. B. de. Processo de Industrialização: do capitalismo originário ao atrasado. São Paulo, SP: Ed. UNESP, 2003. 
PAULA, J. A. de. Celso Furtado, a história e a historiografia. Cadernos do Desenvolvimento, v. 10, n. 17, p. 144-165, 2015.

PELÁEZ, C. M. História da industrialização brasileira. Rio de Janeiro: APEC Editora, 1972.

POLANYI, K. A Grande Transformação: as origens da nossa época. 2a. ed. Rio de Janeiro, RJ: Elsevier, 2012.

PRADO JR., Caio. Formação do Brasil Contemporâneo: colônia. 23. ed. São Paulo, SP: Brasiliense, 2008.

RICUPERO, B. Celso Furtado e o pensamento social brasileiro. In: LIMAS, M. C.; DAVID, M. D. (Org.). A atualidade do pensamento de Celso Furtado. São Paulo: Francis, 2008. p. 19-26.

RODRÍGUEZ, O. O estruturalismo latino-americano. Rio de Janeiro: Civilização Brasileira, 2009.

SÁ, P. Resenha. In: FURTADO, C.; FURTADO, R. F. d'Aguiar (Org.). Formação Econômica do Brasil: edição comemorativa: 50 anos. São Paulo: Companhia das Letras, 2009. p. 361-366.

SACHS, I. Resenha. In: FURTADO, C.; FURTADO, R. F. d"Aguiar (Org.). Formação Econômica do Brasil: edição comemorativa: 50 anos. São Paulo: Companhia das Letras, 2009. p. 427-431.

SANTOS, F.P. dos. O enfoque histórico-estrutural e a crítica relegada. Textos de Economia, v. 14, n. 1, p. 51-81, 2011.

SANTOS, W. G. dos. O ex-Leviatã brasileiro: do voto disperso ao clientelismo concentrado. Rio de Janeiro: Civilização Brasileira, 2006.

SINGER, P. Resenha. In: FURTADO, C.; FURTADO, R. F. d'Aguiar(Org.). Formação Econômica do Brasil: edição comemorativa: 50 anos. São Paulo: Companhia das Letras, 2009. p. 367-370.

SODRÉ, N. W. Resenha. In: FURTADO, C.; D'AGUIAR, R. F. (Org.). Formação Econômica do Brasil: edição comemorativa: 50 anos. São Paulo: Companhia das Letras, 2009. p. 347-349.

SUNKEL, O.; PAZ, P. El subdesarrollo latinoamericano y la teoría del desarrollo. 6. ed. ed. México: Siglo Veintiuno Editores, 1970.

SZMRECSÁNYI, T. Resenha. In: FURTADO, C.; FURTADO, R. F. d'Aguiar (Org.).

Formação Econômica do Brasil: edição comemorativa: 50 anos. São Paulo:

Companhia das Letras, 2009. p. 510-518.

TAVARES, M. C. Acumulação de capital e industrialização no Brasil. 3. ed. Campinas, 
SP: Unicamp, IE, 1998.

TILLY, C. Big structures, large processes, huge comparisons. New York, N. Y.: Russell Sage Foundation, 1984.

VALENTE, M. A. Celso Furtado e os fundamentos de uma economia política republicana. Tese (Doutorado) ed. Florianópolis: Universidade Federal de Santa Catarina, Centro de Filosofia e Ciências Humanas, Programa de Pós-Graduação em Sociologia Política, 2009.

VIEIRA, P. A. A economia-mundo, Portugal e o "Brasil" no longo século XVI (1450-1650). In: VIEIRA, P. A.; FILOMENO, F. A.; VIEIRA, R. de L. (Org.). O Brasil e o capitalismo histórico: passado e presente na análise dos sistemas-mundo. São Paulo, SP: Cultura Acadêmica, 2012. p. 207-264.

VIEIRA, P. A. "Brazil" in the Capitalist World-Economy from 1550 to c. 1800. Review (Fernand Braudel Center), v. 37, n. 1, p. 1-34, 2014. Disponível em: <https://www.jstor.org/stable/90007840>. Acesso em: 25 fev. 2020.

VIEIRA, R. de L. A cadeia mercantil do café produzido no Brasil entre 1830 e 1929. O Brasil e o Capitalismo Histórico: Passado e Presente na Análise dos SistemasMundo. São Paulo: Cultura Acadêmica, 2012. p. 265-296.

WÖHLCKE, M. Resenha. In: FURTADO, C.; FURTADO, R. F. d'Aguiar(Org.). Formação Econômica do Brasil: edição comemorativa: 50 anos. São Paulo: Companhia das Letras, 2009. p. 467-469.

\section{NOTAS}

Doutor em Desenvolvimento Econômico pela Universidade Estadual de Campinas (Unicamp). Atualmente é professor adjunto do Departamento de Economia e Relações Internacionais da Universidade Federal de Santa Catarina (UFSC) 